\title{
AUTOMATIC MONITORING OF VALVE STATUS
}

\author{
Report to the \\ U.S. Department of Energy \\ Deputy Assistant Secretary \\ for Breeder Reactor Programs \\ Washington, D.C. 20545
}

\author{
F. B. Prinz \\ J. H. Chern \\ Department of Mechanical Engineering \\ Carnegie Mellon University \\ Pittsburgh, PA 15213
}

\section{January 1988}

\section{DISCLAIMER}

This report was prepared as an account of work sponsored by an agency of the United States Government. Neither the United States Government nor any agency thereof, nor any of their employees, makes any warranty, express or implied, or assumes any legal liability or responsibility for the accuracy, completeness, or usefulness of any information, apparatus, product, or process disclosed, or represents that its use would not infringe privately owned rights. Reference herein to any specific commercial product, process, or service by trade name, trademark, manufacturer, or otherwise does not necessarily constitute or imply its endorsement, recommendation, or favoring by the United States Government or any agency thereof. The views and opinions of authors expressed herein do not necessarily state or reflect those of the United States Government or any agency thereof.

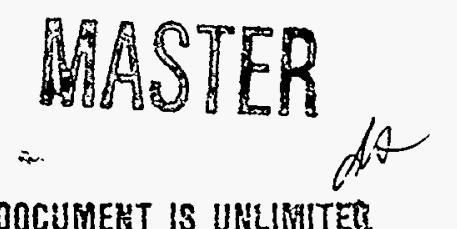

BDTRBBUTION OF THIS DOCUMEHT IS UNLIAITER 


\section{DISCLAIMER}

Portions of this document may be illegible in electronic image products. Images are produced from the best available original document. 


\section{INTRODUCTION}

Nuclear plants operate nominally at 600 degrees F. Valves leaking potentially hazardous material or water can cause serious burns to the maintenance personnel. In addition to safety considerations, there are also monetary losses. Many forced outages at power plants are due to valve leaks. Valves represent approximately $10-12 \%$ of maintenance budgets. Over a three-year period for one power plant, this equalled upwards of $\$ 10$ million [1]. Cost and safety providing strong motivation for the power plant industry to study the problem of valve leakage.

The operation of power plants requires the inspection of hundreds of valves. Reliable information regarding the status of all valves is of vital importance to ensure the safe operation of a power plant. Considering that there may be literally thousands of valves in a power plant, it is not feasible to install all the contact sensors (thermometer, pressure gauge, strain gauge, transducer and flow meter etc.) to obtain information about the operating valve status. It would not only be uneconomical to install these sensors, but also difficult to monitor them and keep them reliable. In addition, many hazardous places are inaccessible to persons performing surveillance.

Power plant valves vary in types, sizes, functions, control mechanisms, etc. and can be operated at various temperatures or pressure systems. The problem associated with determining valve status can be quite complicated. But conceptully it can be easy to detect. One way of detecting the leakage problem requires obtaining the temperature profile of the piping system. Then the temperature gradient can be derived from the temperature profile. Physically, the thermal gradient is related to the heat transfer process. If one can understand and establish the relationship between the thermal gradient and the valve leaking, then one can determine if the operating valve is internally leaking. If it does leak, one can find to what rate of leakage.

In the past decade, power plant leakage problem was investigated by using the acoustic emission (AE) technique [2] [3] [4]. By attaching accoustic sensors to the valve and adjacent pipe, the obtained ultrasonic acoustic emissions can be used to identify the corresponding leaking process and the leakage rate. However, difficulties arise in identifying the source mechanisms in a leaking valve due to turbulence, cavitation, flashing of liquid to vapor and mechanical movement of parts. In reality these generating mechanisms themselves interact and the AE observed is a sum from all sources and cannot be separated into source mechanisms. Therefore, the contributing mechanisms may not be identifiable. 


\section{APPROARCH}

An exact solution for determining the temperature profile of a valve leaking problem, together with convection and radiation heat transfer, can be complicated. It involves difficulties and uncertainties in modeling of the valve intemal leaking process and complex geometry of surface, boundary conditions, thermal resistance for contacting between valve and insulation material(s).

Approximating the temperature gradient for various flow rates was done by simulating of a piping system or from experimental results. Approximation was made first for finding thermal gradient. In this approximation, individual valve leakage location was not determined. And a simple relation was derived between the leakage rate and the temperature gradient. Details of the analysis are attached in the appendix.

A steady-state temperature profile was obtained for reference by using numerical approximation. A finite element model of pipe flow [5] was chosen to approximate temperature distributions, given piping system characteristics such as: valve type and material; pipe material, diameter and thickness; insulation type and thickness; leakage rates, etc.

A mock-up of a piping system has been constructed that simulates the conditions of a typical piping section in a power plant. An infrared sensor was used to obtain the temperature profile outside the piping system. Details of system description can be found from the appendix.

Having the temperature gradient information, another portion of work is to compare the actual temperature gradient to those approximated temperature gradients. This can be done by selecting certain feature points on both valve and pipe portions, and then comparing the corresponding thermal gradient. Since the measured temperature profile contains noise (arising from analog/digital conversion, the accuracy of the measuring device and the uncertainity of radiation emissivity), a smoothing operation can be used to filter and reduce noise level before doing comparion.

Fig. 1 shows the experimental results obtained from the mock-up system. Fig.2 is the temperature distributions obtained by FEM approximation. Inconsistancy arises in comparing the approximating temperature gradients to the actual temperature gradient. Error was found from the simulation of leakage in a valve and was due to coarse control of the valve opening in the mock system. Other possible reasons to explain the inconsistancy can be due to the over-simplified model and experimental error in controling 
very fine flow rate of the diagram valve. In addition, the mock system may not be fully representable to a real power plant system andcan have different steady-state temperature distribution from the real system. Furthermore, the mock-up system has relatively low operating temperature (around 200 degree F) and good insulation material (0.5", 1.0" fiber-glass). Because of this low temperature and good insulation,the outside temperature gradient of insulation is almost a constant over the first few feet. In fact, a good insulation layer was usually used to prevent heat loss from the piping system and thus block this noncontacted heat detection process.

\section{FUTURE RESEARCH}

Further study can be made in the following considerations:

- to incorporate with the power plant and use infrared sensing to obtain the normal operating temperature profile

- to extract common and key features from thermal distribution understand the leakage problem

- to establish a data base record that contains the normal operating valve and piping system temperature distribution and selected leaking signature and apply the numerical smoothing and differentation technique such that a proper inverse solution can be found to identify the corresponding leaks using non-absolute temperature scaling.

\section{SUMMARY}

In the planning for modem nuclear power plants, features can be integrated for accomodating a remotely controlled or autonomous vehicle. The user of the remotely controlled vehicle could identify the location of the valve in question. The temperature profile could be obtained by infrared sensor. Leak detection by the analysis and comparison of valve thermal signature could then be done in an automatic fashion. The non-contact valve leak detection and thermal gradient comparison technique can be useful in power plant maintenance. 


\section{APPENDIX}

\subsection{SYSTEM DESCRIPTION}

Currently, the infrared sensor and vision camera are mounted on a robot manipulator, a GMF-110 robot, which has six degrees of freedom to manipulate sensors within its envelope. The vision system will first determine the right location of the valve. After that the infrared sensor collects the temperature data from the valve itself, and piping upstream and downstream of the valve. The materials and hardware chosen for the test were those normally found in typical power plant piping sytems. The test valve chosen for this experiment is a 4" diaphragm valve. All piping, tubing, fittings, and auxilliary valves are of stainless steel, and ball valves were chosen for the auxilliary valves. An isometric diagram of the piping system is illustrated in Fig.3.

The integration of the infrared sensor, vision camera, and robotic systems is illustrated schematically in Fig.4. The robot manipulator is programmed to follow a prescribed path by the robot controller and sweeps across the piping and valve. The vision camera locates the position of the valve, while the infrared sensor mounted on the manipulator, shown in Fig.5, detects the radiation emitted by the piping. This data is then transferred to an AVD convertor which translates this analog signal into digital temperature. Fig. 6 shows the tracking sensor in the process of detecting the position of a diaphragm vavle and the infrared sensor taking the temperature reading.

\subsection{THERMAL ANALYSIS OF A PIPING SECTION}

A simple model is proposed to determine the temperature gradient over a piping section. Two assumptions were made: steady-state conditions exist and phase changing associated with the fluid in the piping system did not exist.

Given a control volume, the thermal balance tells that the amount of heat dissipation through the pipe wall will equal the amount of enthalpy changes, namely

$$
m c_{p} d T_{\text {axial }}=\frac{k_{f} 2 \pi r d x}{\ln \left(r_{p} / r_{i}\right)}\left(T_{p}-T_{i}\right)
$$

or the slope of the temperature distribution

$$
\frac{d T_{\text {axial }}}{d x}=\frac{k_{2} 2 \pi r_{i}}{m c_{p} \ln \left(r_{p} / r_{i}\right)}\left(T_{p}-T_{i}\right)
$$


where $\ln \left(r_{p} / r_{p}\right)$ is the nondimensional thickness, and $m$ is the mass flow rate.

It shows that the temperature slope for a given pipe with a thin layer of insulation and large mass flow rate may have the same slope as a pipe having a thicker insulation and small amount of mass flow rate. Note in Eq.2, both $T_{p}$ and $T_{i}$ are not directly measureable to the infrared sensor.

Applying the energy balance on the piping surface, one can obtain

$$
\frac{d T_{m}}{d x}=\frac{\pi D}{m c_{p}} h\left(T-T_{\infty}\right)
$$

where $T_{m}$ is the mean temperature.

In heat transfer, a free jet occurs when a fluid is discharged from a nozzle or orifice. Since the power plant operation is sensitive to the small valve leak, conceptully one can model the leakage as an orifice and use external free jet model to approximate the distance for the fully-developed region.

Experimental results on laminar circular jets shows the width of the jet is proportional to $x$ and the centerline velocity $u_{c} \sim x^{1}$. According to the measurement performed by $\mathrm{H}$. Reichardt [6] the width of the jet is given by

$$
\delta=0.0848 x
$$

where $\delta$ denotes half-width (as the $y$ distance where $u / u_{c}=1 / 2$ ). For turbulent two-dimensional jets, it was shown [7] that

$$
\delta=0.115 x
$$

Thus, given a certain size of pipe and different kind of valves, the local area and details of the developing jet region is rather complex. Using the result of free jet model will help us in approximating this complex zone. Instead of getting complicated messages from this short region, we can adopt the theoretical convective boundary condition in performing finite element analysis. 


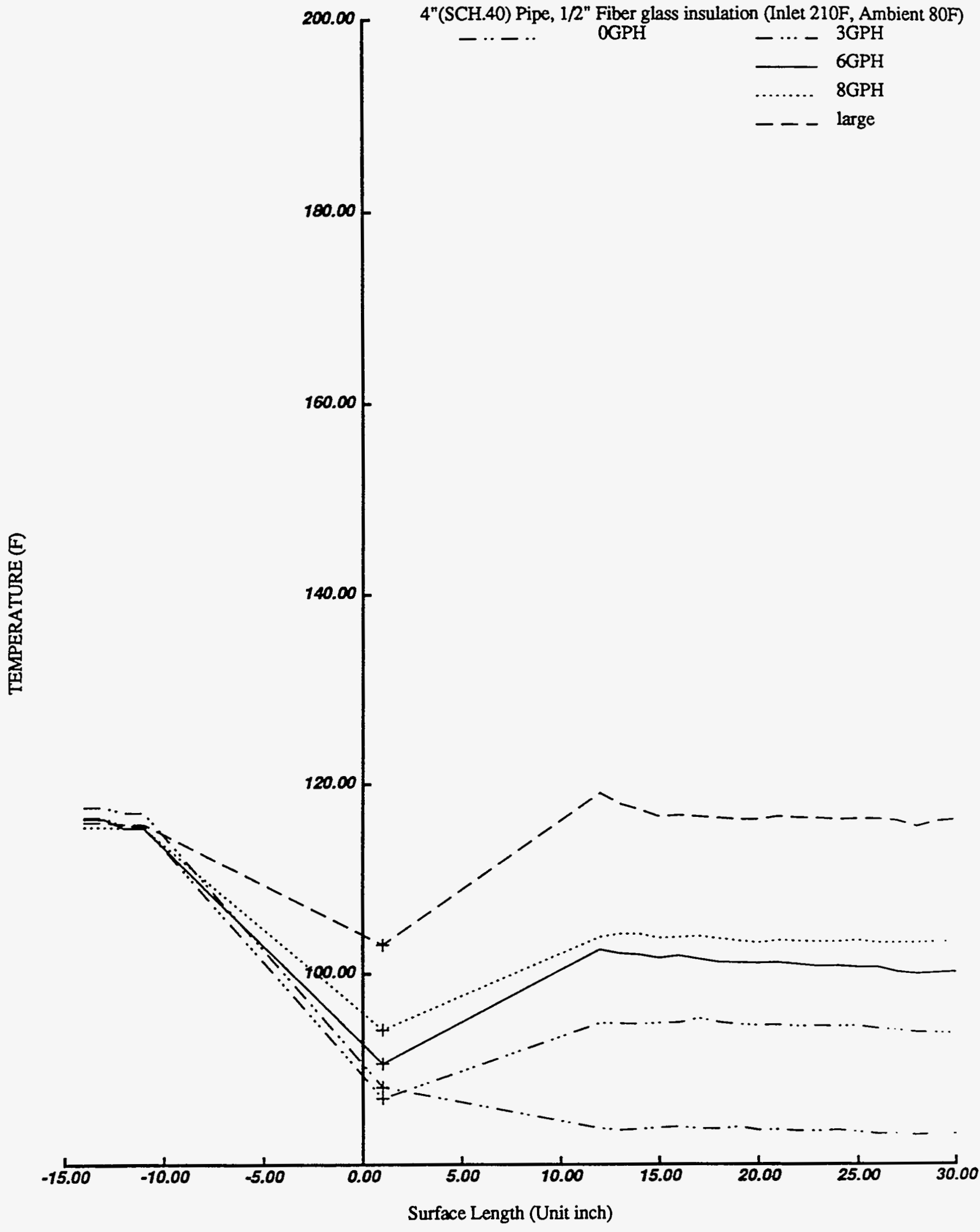

Figure 1: Experimental Temperature Profiles for Mock-up System 


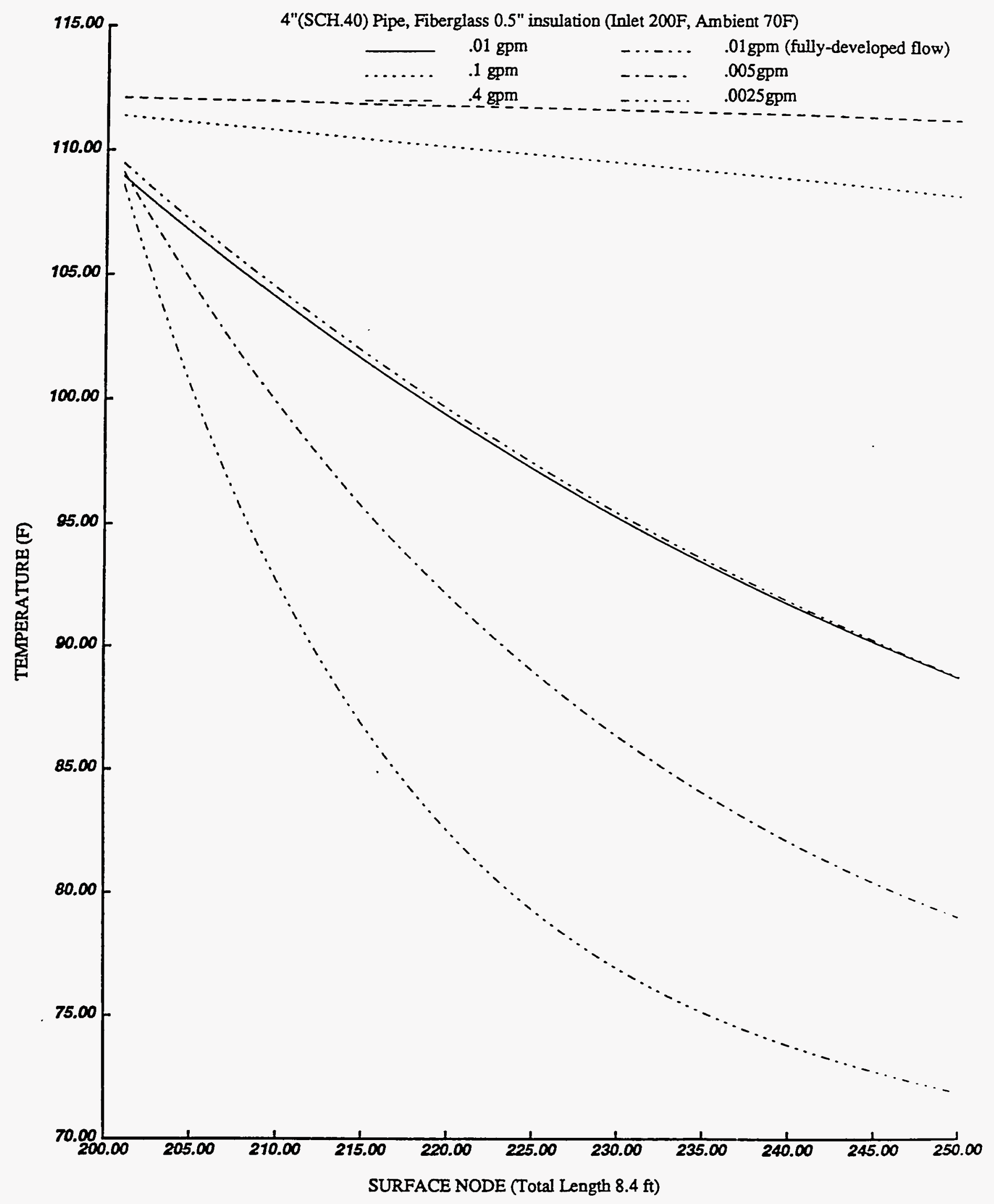

Figure 2: Temperature Profiles from FEM Approximation 


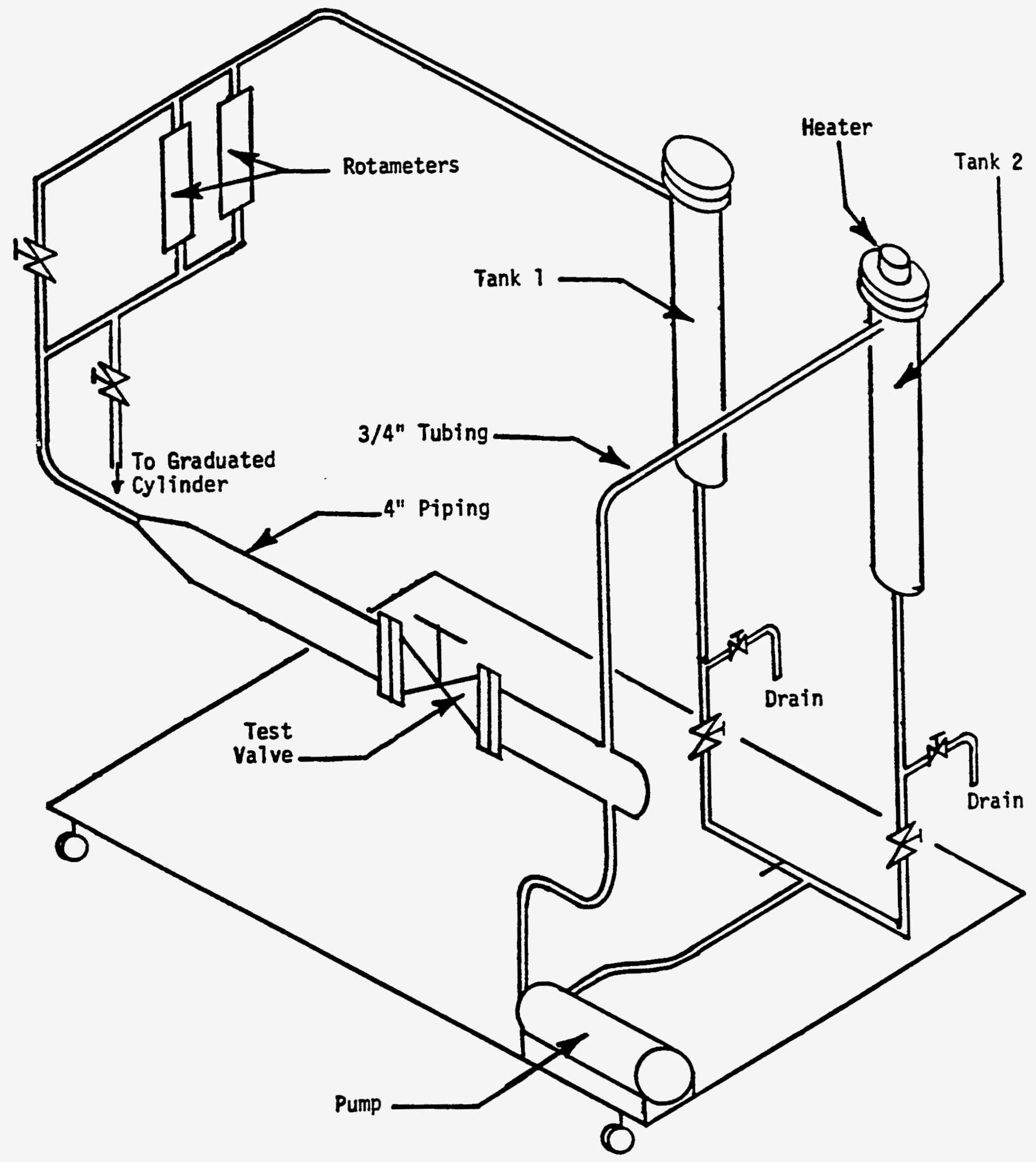

Flgure 3: Piping System Hardware 


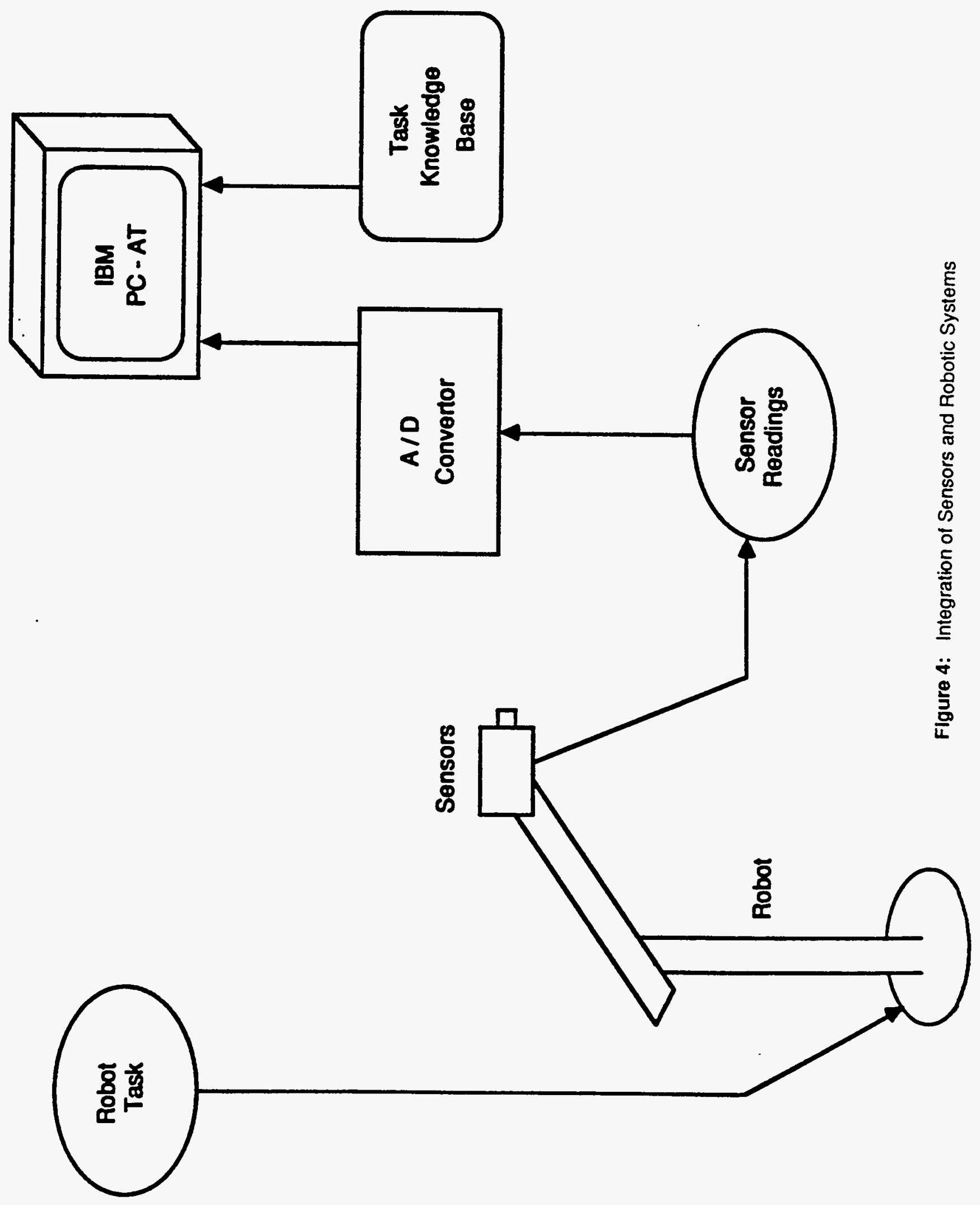



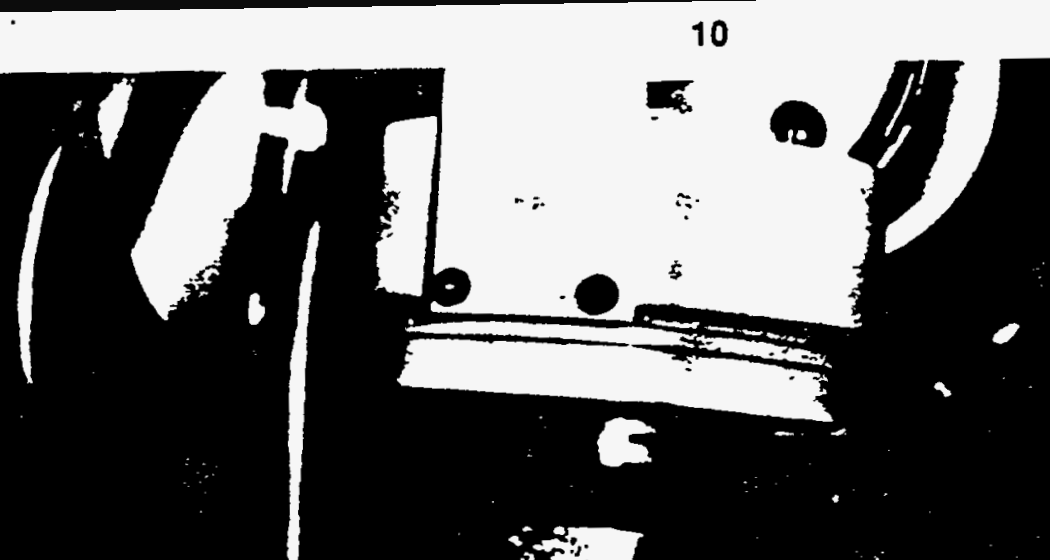


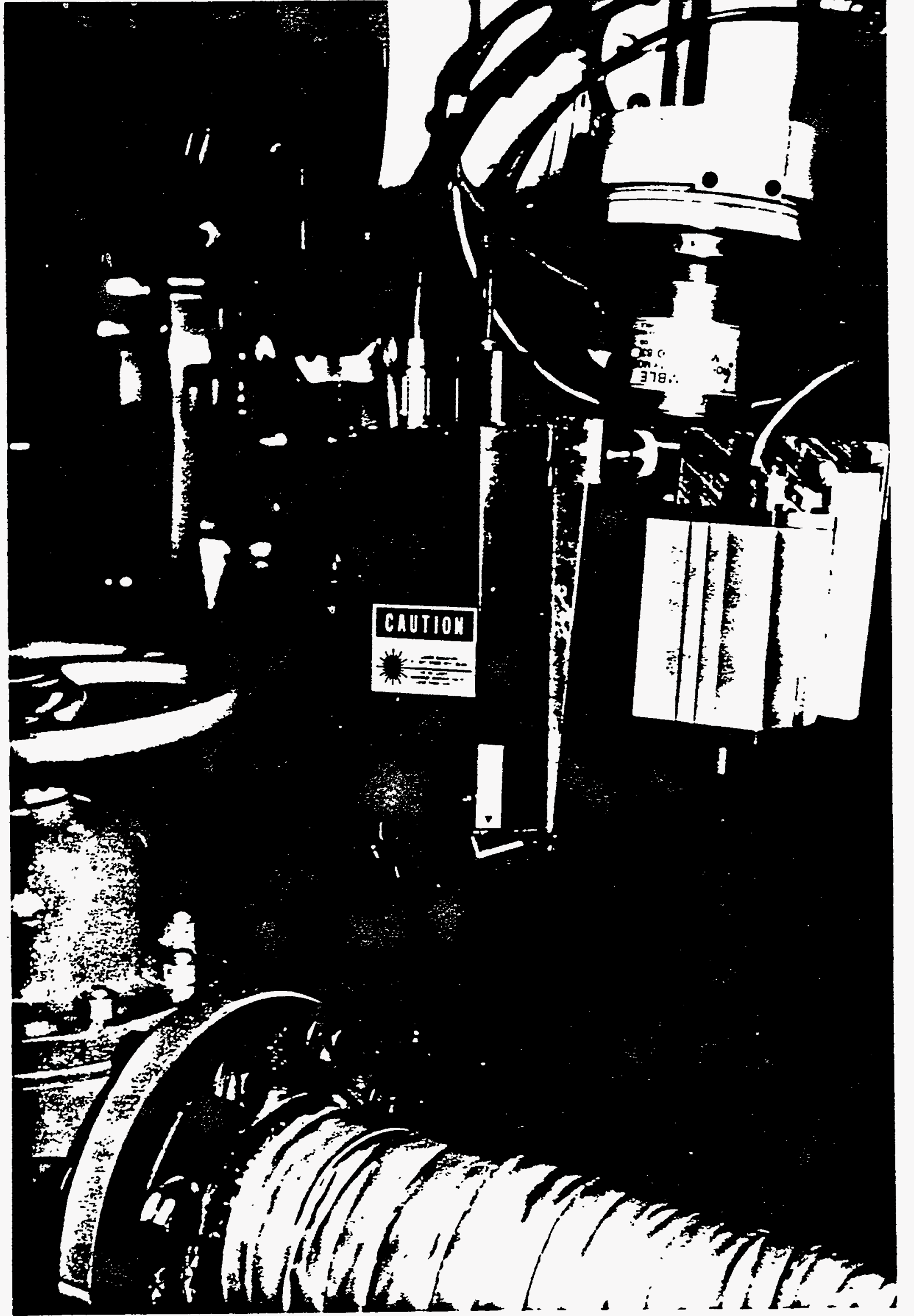

Figure 6: Photograph of a Test Valve and Sensors 


\section{References}

[1] Dimmick, J. G. et al.

Ultransonic detection cuts valve maintenance costs.

Power Engineering :35-38, August, 1986.

[2] Dimmick J. G.; Nicholas J. R. and Moore P. M.

Acoustical Valve Leak Detector for Fluid System Maintenance.

Navel Engineers :71-83, April, 1979.

[3] Allen, J. W., Hartman W. F., Robinson J. C.

Acoustic Monitoring of Power Plant Valves.

Electric Power Research Institute , June, 1982.

[4] Dickey, J.;Dimmick, J. and Moore P.

Acoustic Measurement of Valve Leakage Rates.

Materials Evaluation :67-77, January, 1978.

[5] Edwards, Arthur L.

A Computer Program for Transient and Steady-State Temperature Distributions in Multidimensional Systems

Lawrence Radiation Laboratory, Livermore, California, 1972.

[6] Hermann Schlichting.

Boundary-Layer Theory.

MCGRAW-HILL , 1968.

[7] Tuncer Cebeci \& Peter Bradshaw.

Physical and Computational Aspects of Convective Heat Transfer.

Springer-Verlag, 1984. 


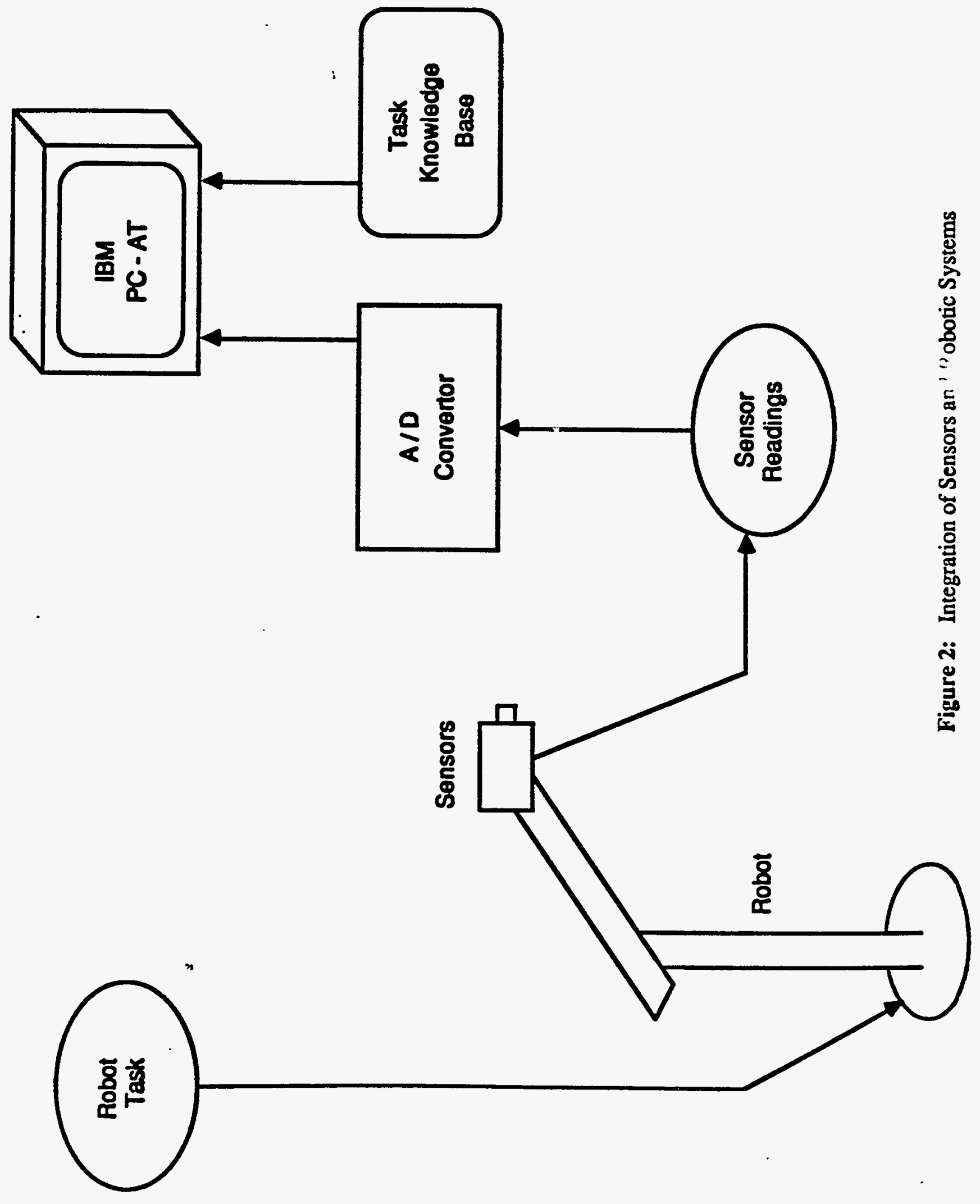




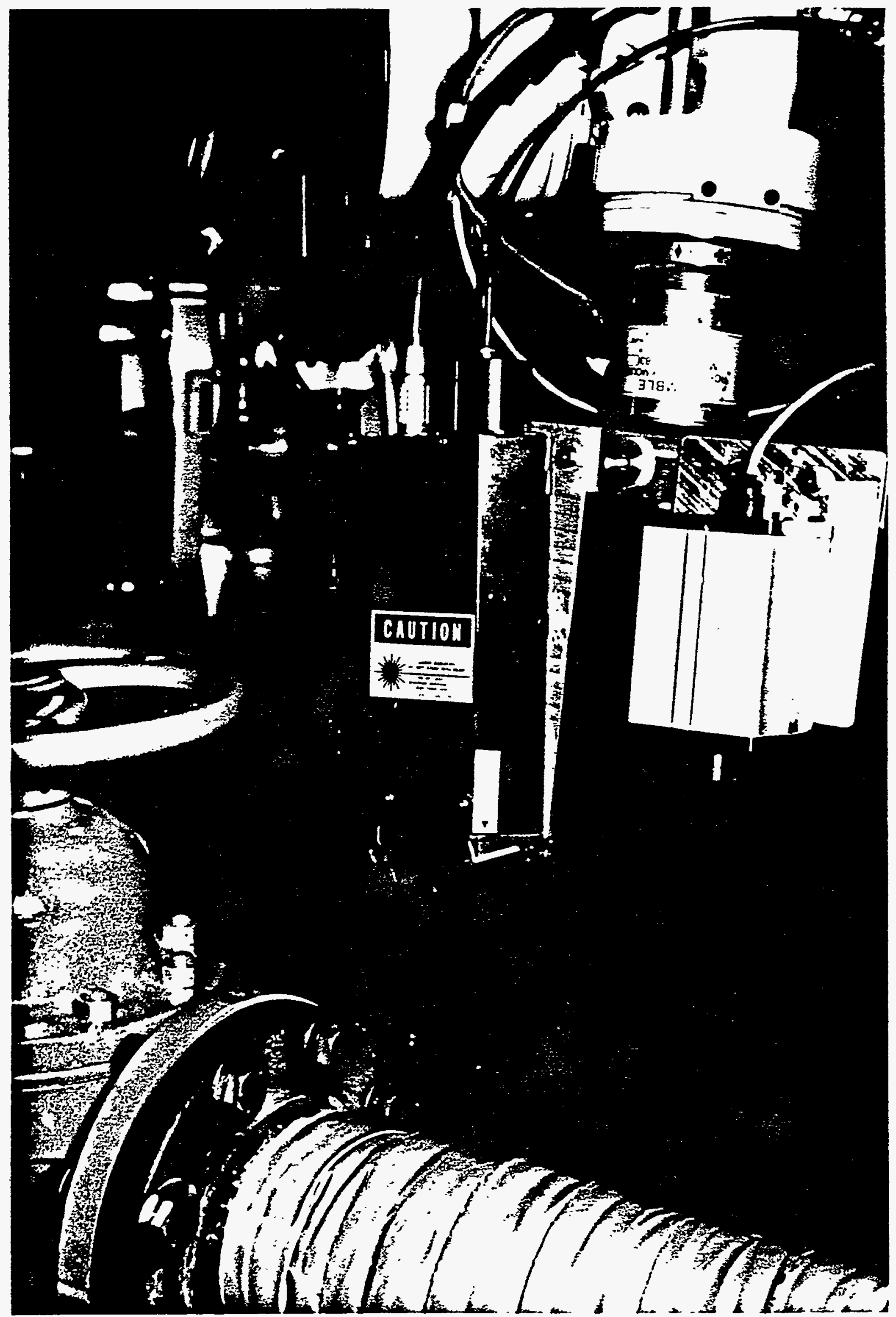

Figure 3: Photograph of Robotic Manipulator with Sensors 


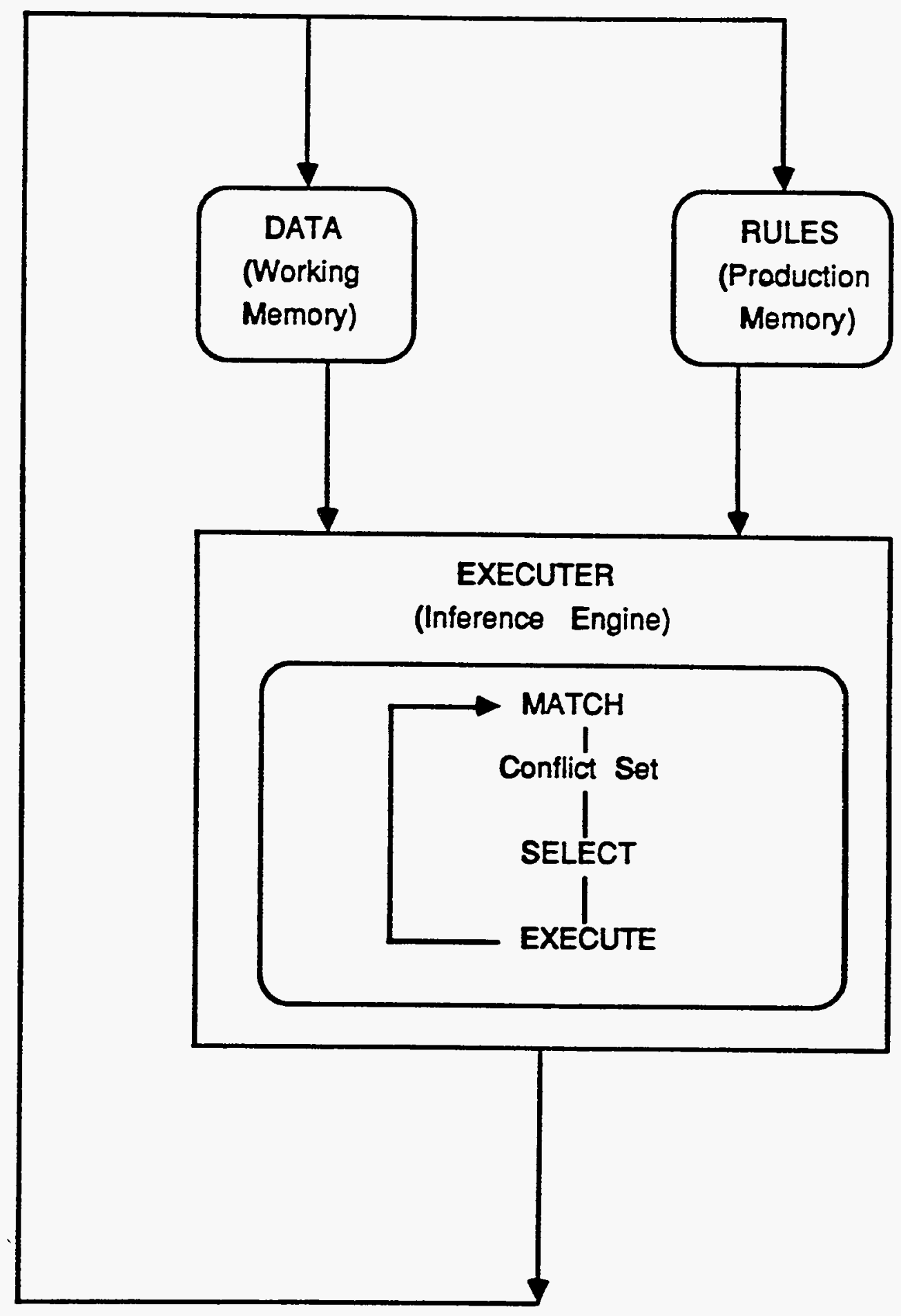

Figure 4: Production-System Structure 


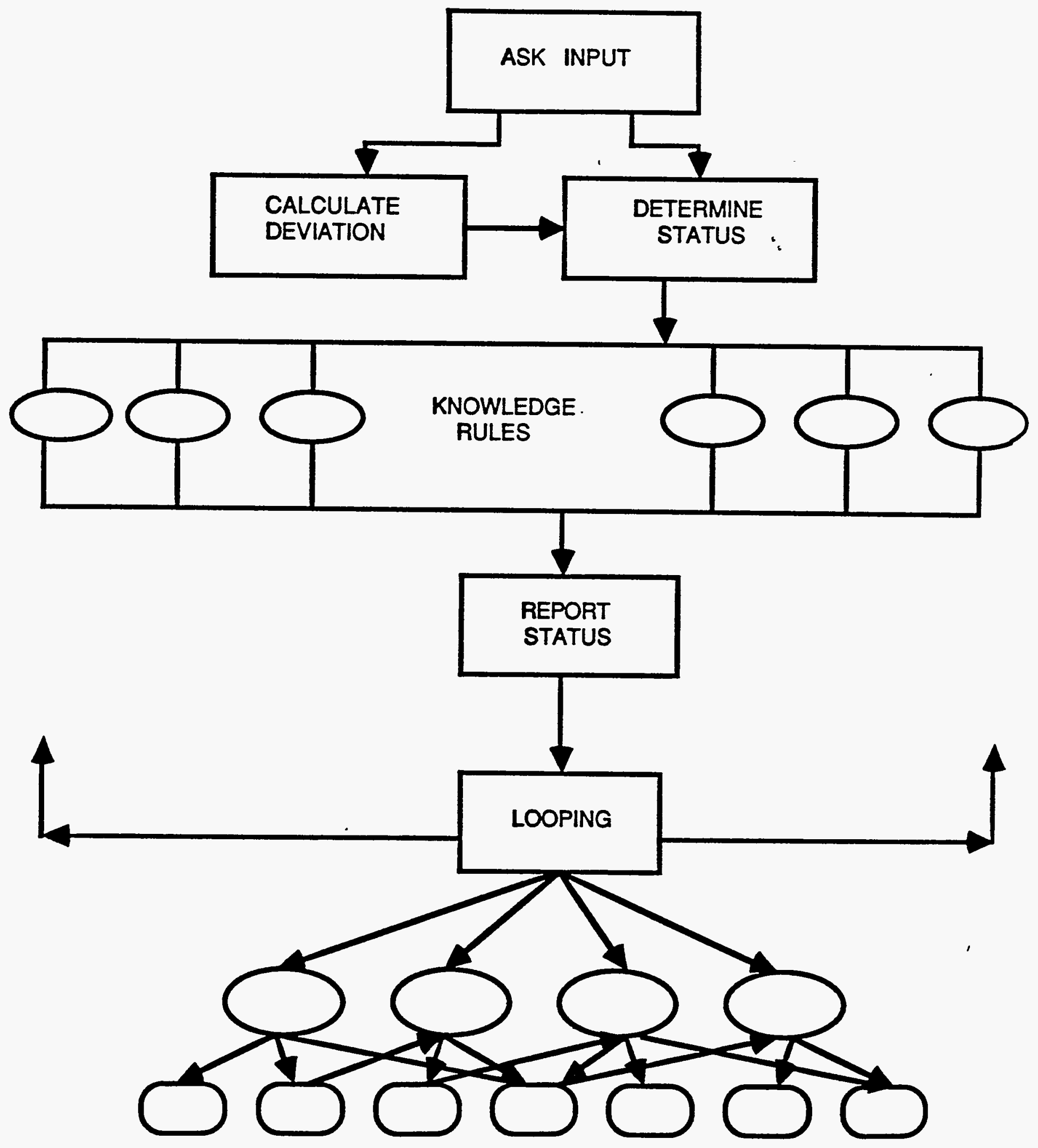

Figure 5: Expert System Production Rules 


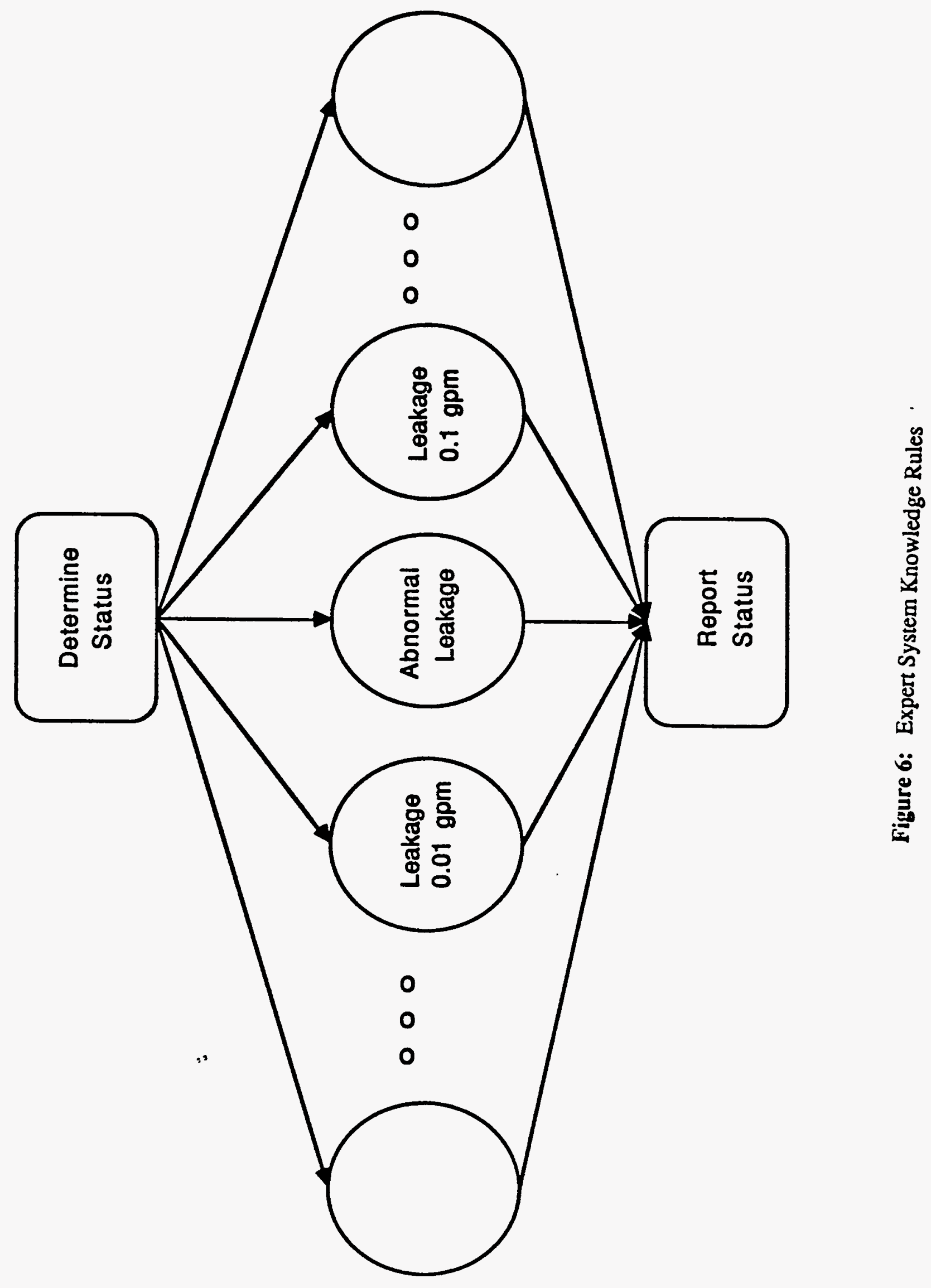




\section{References}

[1] Dimmick, J. G. et al.

Ultransonic detection cuts valve maintenance costs.

Power Engineering :35-38, August, 1986.

[2] Edwards, Arthur L.

A Computer Program for Transient and Steady-State Temperature Distributions in Multidimensional Systems

Lawrence Radiation Laboratory, Livermore, California, 1972.

[3] Brownston, L; Farrell, R; Kant E. and Martin, N.

Programming Expert Systems in OPS5 - An Introduction to Rule-Based Programming.

Addison-Wesley, 1986. 